\title{
Case 2: Market readiness for a residential ventilation system designed for providing better household living conditions and lower energy costs. The case of Lindab in Romania
}

\author{
Tudor EDU* and Iliuta Costel NEGRICEA* \\ *PhD; Associate Professor of Marketing, Romanian-American University, \\ Bucharest, Romania
}

Introduction

In 2016, Lindab Romania wanted to include its product assortment a ventilation system for residential use. In this regard the company is faced with the question of whether such a system would be sought after in Romania. Narrowing down from this problem definition, the present study focuses on uncovering buying and non-buying reasons for such a system in Romania in order to match them with the benefits provided by the ventilation system, which can be effectively summarised in healthier indoor environment and lower electricity and gas bills.

The research methodology was centred on qualitative research in the form of in-depth interviews and group discussions for prompting possible reasons and restrictions for buying a mechanical ventilation system for household purposes.

How to cite this book chapter:

EDU, T. and NEGRICEA, I. C. 2019. Case 2: Market readiness for a residential ventilation system designed for providing better household living conditions and lower energy costs. The case of Lindab in Romania. In: Gąsior, A. (ed.) Pro-ecological Restructuring of Companies: Case Studies, Pp. 199-209. London: Ubiquity Press. DOI: https://doi. org/10.5334/bbk.q. License: CC-BY 4.0 
The main conclusion of the study is that house owners are delighted to have healthier indoor environment and lower electricity and gas bills but very few have the financial means or are willing to invest in acquiring the residential ventilation system.

\section{Research methodology}

The goal of the study being that of uncovering buying and non-buying motives for a new product, qualitative research was considered the most appropriate method because of its effectiveness in understanding issues very seldom easily expressed by individuals, such as values, beliefs or attitudes (Marshall 1996). According to Corbin and Strauss (2014), through qualitative research, consumer experiences can be explored, while Sharan (2009) extends this idea, underlining that even insights attached by consumers to such experiences can be identified. In this case study two qualitative research techniques were selected due to their effectiveness in generating data on topics not previously covered, in-depth interviews and focus groups. The in-depth interview, as a data collection tool, stands out for the richness of the findings (Ritchie, Lewis \& Elam 2003), helping a researcher in understanding why each respondent judges one topic in a particular way (King 2004). On the other hand, the focus group, as a tool for gathering data, represents a group discussion, which is considered to be very effective especially because of the interactions between the members often building up to situations similar to those ones in real life (Kreuger \& Casey 2000). In qualitative research, special consideration should be given to the sampling methodology and sample size. Because the main purpose of using qualitative research is to provide a wealth of data and not to generalise the findings to the entire population, the sampling methodology is a non-random one, the researcher having a wide liberty of including in the sample the respondents deemed most suitable (Malhotra 2010; Coyne 1997). Closely connected with the sampling methodology is the sample size. Unlike quantitative research, the sample size in qualitative research is small. According to Marshall, Cardon, Poddar and Fontenot (2013), Morse (1994), Bernard (2000) and Creswell (1998) a sample of at least 30 individuals would deliver appropriate findings when using in-depth interviews, while according to Finch and Lewis (2003), six to eight individuals or, according to Malhotra (2010), eight to 12 individuals per each focus group should be considered in two to three group discussions for about $80 \%$ theme coverage or three to six group discussions for about $90 \%$ theme coverage (Guest, Namey \& McKenna 2016).

The data collection in this study was performed based on a group discussion moderated by the researchers and semi-structured in-depth interviews also conducted by the researchers.

A judgemental sample of 44 individuals was considered comprising people from four groups: 
1. individuals building a house or planning to build one: 8 people

2. individuals who bought Lindab products in the past 12 months: 9 people

3. Lindab's sales agents: 28 people

4. Lindab's partners: 5 people

The judgemental sampling procedure was chosen for several reasons:

- To collect data from all stakeholders

- To build a comprehensive understanding of the research goal

- To perform an exploratory research, meaning to uncover answers to "why questions" and not to "how many or how often"

\section{Lindab - An International Leader in Construction Solutions}

Lindab claims, "Simplifying is our passion, ultimate comfort is our vision".

Lindab is a leading international manufacturer of industrial and residential construction solutions based in Sweden but currently present in 32 countries. According to the Interim report (Lindab 2016a), Lindab recorded, in 2015, sales of approximately 812 million EUR, employing around 5100 people and making about $80 \%$ of its sales from the non-residential sector. Geographically, the biggest part of its sales (44\%) came from the Nordic countries, followed by Western Europe (33\%), Central and Eastern Europe and other Soviet states (19\%) and other markets (4\%). Lindab has a network of 140 branches and around 3000 partners (Lindab 2016a).

Lindab defines itself as an innovator, delivering top quality energy-efficient and environmentally friendly products focused on improving the standard of living (Lindab 2016b). By aiming at comfort and simplicity, Lindab strives to be recognised as a pillar of sustainable building, Corporate Social Responsibility actions being at the forefront of all business endeavours (Lindab 2016c). Lindab markets five groups of products and solutions: building products, covering floors, walls and roofs; building solutions for residential and industrial purposes; ventilation products; indoor climate solutions (air diffusers, waterborne climate systems and acoustics) and complete building systems for industrial purposes (Lindab 2016d).

The residential ventilation system was designed by Lindab to be implemented in dwellings focusing on three aspects: energy consumption, indoor climate and recurrent costs. The benefits rendered by the residential ventilation system can be summarised in healthier indoor climate (supressing pollen, moisture, mould and condensation), lower running costs (the system saving up to $7000 \mathrm{kWh} /$ apartment/year), easy maintenance and a nice design of the equipment, ducts and valves. From a technical perspective, the ventilation system is an integrated solution comprising a double-flow heat recovery system, filtering and warming or cooling the incoming air, an airtight system of ducts, and valves and grills. 
All these components can be blended perfectly with various types of interior designs. Lindab offers the residential ventilation system as a turn-key solution including counselling, deploying and maintenance (Lindab 2016e).

\section{Market Readiness for the Residential Ventilation System in Romania}

The research goal, that of uncovering buying and non-buying motives for the residential ventilation system in Romania, was split into eight objectives, five common to all groups and three appropriate for either one or two groups, covering the following areas:

- identifying meanings pertaining to mechanical ventilation given by individuals currently building a house or planning to build one - objective set for prospects

- identifying if the mechanical ventilation system would be purchased based on the benefits rendered through its features:

- healthier indoor environment

- lower home heating and/or cooling bill

- identifying if prospects would pay a price ranging between 3500 and 4000 EUR (+VAT) for the mechanical ventilation system considering an investment recovery time frame of eight to 11 years

- identifying if a payment plan including maintenance would be an incentive for a prospect in buying the mechanical ventilation system

- identifying if a discount ranging between $10 \%$ and $20 \%$ would be an incentive for a prospect in buying the mechanical ventilation system

- identifying if a prospect would rather work with only one supplier or several suppliers considering the incurred costs

- identifying reasons for buying or rejecting the mechanical ventilation system by prospects if the cost would not be a constraint - objective for prospects

- identifying the construction stage at which Lindab's sales agents and partners should approach a prospect about the mechanical ventilation system - objective for sales agents and partners

Five instruments were designed for collecting data. For each group of respondents under investigation semi-structured in-depth interviews were used while for the sales agents a focus group was organised additionally to the in-depth interviews (see Table 1).

The data analysis was performed using content analysis for each sample group, considering that some research objectives were formulated for one or two groups. 
Table 1: Groups and research instruments.

\begin{tabular}{|l|l|}
\hline \multicolumn{1}{|c|}{ Group and sample size } & $\begin{array}{l}\text { Type of qualitative research instrument } \\
\text { used }\end{array}$ \\
\hline $\begin{array}{l}\text { Individuals building a house or planning } \\
\text { to build one: } 8 \text { people }\end{array}$ & In-depth interviews (8 interviews) \\
\hline $\begin{array}{l}\text { Individuals who bought Lindab products } \\
\text { in the past 12 months: 9 people }\end{array}$ & In-depth interviews (9 interviews) \\
\hline Lindab's sales agents: 28 people & $\begin{array}{l}\text { In-depth interviews (22 interviews) and } \\
\text { focus group (1 group discussion }-6 \\
\text { people) }\end{array}$ \\
\hline Lindab's partners: 5 people & In-depth interviews (5 interviews) \\
\hline
\end{tabular}

Source: developed by the authors.

The research objectives were used to build the discussion topics for each group under investigation. The discussion topics and the appropriate conclusions for each group are presented below.

\section{Group 1 - Individuals building a house or planning to build one}

For this group, nine discussion topics were developed to provide answers necessary to cover the formulated objectives:

1. Meanings given to ventilation

2. Advantages of a mechanical ventilation system

3. Buying intention based on healthier indoor environment as a benefit provided by the mechanical ventilation system

4. Buying intention based on lower heating and/or cooling costs as benefits provided by the mechanical ventilation system

5. Opinions about the appropriateness of buying the mechanical ventilation system based on an investment recovery within a period of eight to 11 years

6. Opinions about paying a price ranging between 3500 and 4000 EUR (+VAT) for the mechanical ventilation system

7. Opinions related to a payment plan for the mechanical ventilation system

8. Opinions about working with a single company or several companies for installing the mechanical ventilation system considering the incurred costs

9. Opinions related to the appropriateness of buying the mechanical ventilation system if its cost would not be an issue 
Main findings for this group:

The prospect is aware of the home ventilation need in order to maintain a healthy indoor climate and provide better well-being for the entire family. Although many prospects overlap mechanical ventilation and air conditioning, they comprehend the benefits of a mechanical ventilation system (MVS) in the form of maintaining health, keeping constant ambient temperature, heating/cooling cost efficiency and convenience. Cuts in the heating/cooling expenses are an argument that can justify buying an MVS. But the cost reduction is placed in the context of the total cost and product lifetime expectancy. Also, the health benefits are a strong incentive in buying the MVS, but one cannot discriminate which one is more important. The prospects consider that the 8-11-year return-on-investment interval is too long, this being correlated with their opinions on the acquisition price, the MVS being considered expensive. On the other hand, a payment plan is considered a good idea by the prospects, but a monthly instalment of 150 EUR is perceived as being too strenuous on the budget, alternatives with lower monthly fees and longer period of times being considered more suitable. Some prospects would consider installing the MVS with several companies due to cost reasons while other prospects are open towards deploying the MVS with a single company to control the process. In conclusion, the MVS is highly commended by the prospects, the only hindrance in acquiring it being its cost.

\section{Group 2 - Individuals who bought Lindab products in the past 12 months}

For this group, six discussion topics were developed to provide answers necessary to cover the formulated objectives:

1. Buying intention based on healthier indoor environment as a benefit provided by the mechanical ventilation system

2. Buying intention based on lower heating and/or cooling costs as benefits provided by the mechanical ventilation system

3. Opinions about the appropriateness of buying the mechanical ventilation system based on investment recovery within a period of eight to 11 years

4. Opinions about paying a price ranging between 3500 and 4000 EUR (+VAT) for the mechanical ventilation system

5. Opinions related to a payment plan for the mechanical ventilation system

6. Opinions about working with a single company or several companies for installing the mechanical ventilation system considering the incurred costs

Main findings for this group:

For Lindab's current customers (for other products than the mechanical ventilation system) the reasons for purchasing the mechanical ventilation system 
(MVS) are mainly rational. The family health benefits seem to be less important than rational elements like the return on investment or MVS's installation or maintenance costs. It is also mentioned that the MVS is feasible for polluted and crowded areas, for office buildings and less adequate for residential ones. Lindab's current customers consider that lowering the actual costs of house heating/cooling costs is the main acquisition reason of the MVS. Because Lindab's current customers are technically and financially proficient in what it takes to build a house, it is advisable that rational explanations of the cost reduction through the usage of the MVS be properly communicated. These rational explanations can be the strongest argument in convincing this segment about the benefits of the MVS. The 8-11-year return-on-investment time frame is considered too long. The underlying reasons for this conclusion are the system's lifetime expectancy and the envisaged high maintenance costs. Lindab's current customers (for other products than the MVS) would prefer a shorter returnon-investment time interval. The acceptance of a 3500-4000 EUR (plus VAT) price is correlated with the effort incurred in the structural changes necessary to install the system and with the costs of the interior design changes. The price level is directly related to the health and financial benefits rendered by the MVS. Also, the competitive advantage and the lifetime expectancy are important in the MVS's price acceptance. A payment plan is not considered an incentive but it can be taken into consideration if the instalments are advantageous and the interest rate is low. However, a monthly rate of 150 EUR is considered high, many respondents believing that such an instalment is an important element in the procurement process of the MVS. Buying an MVS from one supplier is acceptable to Lindab's current clients. Quality, risk reduction activities and capabilities related with installation, operation and maintenance are the main reasons supporting a buying decision.

\section{Group 3 - Lindab's sales agents}

For this group, ten discussion topics were developed to provide answers necessary to cover the formulated objectives, the data being gathered in a focus group and through in-depth interviews:

1. Buying intention based on healthier indoor environment as a benefit provided by the mechanical ventilation system

2. Buying intention based on lower heating costs as benefits provided by the mechanical ventilation system

3. Buying intention based on cooler indoor temperature through fresh air in-take as a benefit provided by the mechanical ventilation system

4. Opinions about the appropriateness of buying the mechanical ventilation system based on investment recovery within a period of eight to 11 years 
5. Opinions about paying a price ranging between 3500 and 4000 EUR (+VAT) for the mechanical ventilation system

6. Buying intention based on a $10 \%$ discount offered to the prospect

7. Opinions related to a payment plan for the mechanical ventilation system

8. Opinions about working with a single company or several companies for installing the mechanical ventilation system considering the incurred costs

9. Opinions about the most appropriate construction phase for approaching a prospect for the mechanical ventilation system

10. Opinions about the appropriateness of introducing the mechanical ventilation system in Lindab's product assortment

Main findings for this group:

Lindab's sales agents presume that the mechanical ventilation system (MVS) would be purchased for residential purposes by individuals with medium-tohigh income for the health benefits rendered by the MVS. The sales agents believe that these benefits are more important than the money the prospects can save on heating/cooling bills. Also, linked with the customer profile (medium-to-high income and health benefits), the agents presume that the MVS will sell even better if integrated with new heating/cooling technologies. Also, they believe the difference between air conditioning systems and the MVS is not clear and prospects would not buy the MVS because it can cool or heat premises considering its price unless the MVS's features are thoroughly explained and documented. The 8-11-year return-on-investment time frame is considered too long by most sales agents. However, a few sales agents consider this time frame to be a benefit but this should be properly documented. The sales agents consider, as mentioned above, that the MVS would be acquired mainly by individuals with medium-to-high income that value highly the health benefits but they believe that a discount of at least $10 \%$ would speed up the selling process and lure in more prospects. A payment plan is considered a suitable alternative for attracting more prospects as a significant number of prospects discover the appropriateness of a ventilation system while they are in the building process and such a system is not initially budgeted. The sales agents have mixed feelings concerning the prospects' tendencies of working with a single business or several companies when installing a ventilation system. Those underlining one company emphasise trust and less effort from the prospects while those mentioning several companies focus on smaller costs. The sales agents believe the MVS can be proposed to the market in all construction stages. Most importantly, the sales agents strongly believe that the MVS can be a successful product and should be included in Lindab's portfolio primarily due to its features covering health and welfare as it will render more sales especially cross-sold with the roofing systems. 


\section{Group 4 - Lindab's partners}

For this group, seven discussion topics were developed to provide answers necessary to cover the formulated objectives in in-depth interviews:

1. Buying intention based on healthier indoor environment as a benefit provided by the mechanical ventilation system

2. Buying intention based on lower cooling/heating costs as benefits provided by the mechanical ventilation system

3. Opinions about the appropriateness of buying the mechanical ventilation system based on investment recovery within a period of eight to 11 years

4. Opinions about paying a price ranging between 3500 and 4000 EUR (+VAT) for the mechanical ventilation system

5. Opinions related to a payment plan for the mechanical ventilation system

6. Opinions about working with a single company or several companies for installing the mechanical ventilation system considering the incurred costs

7. Opinions about the most appropriate construction phase for approaching a prospect for the mechanical ventilation system

Main findings for this group:

Lindab's partners believe that the Mechanical Ventilation System (MVS) would be purchased by individuals for the health benefits but by the affluent ones (medium to high income) as in many cases they value more the health benefits in comparison to the financial/cost ones. This is in sync with what the partners believe about the return-on-investment time frame (8-11 years) as being too long and not an adequate idea to use in the marketing communication. Also, considering the MVS's acquisition price, the partners believe that the price is high and Lindab should target prospects with medium to high income. The partners believe that a payment plan for the MVS would enlarge the opportunity pool by raising interest from more prospects but they underlined the fact that they would not want to be involved in financing the MVS. The partners believe that most prospects would want to work with a single company for installing a ventilation system being open to pay a higher price but not exceeding 20-30\%. The partners also believe that the MVS can be proposed to prospects in all construction stages of a house.

\section{Conclusions}

This research sheds some light on motives for buying and not buying the mechanical ventilation system (MVS). The most important reasons for buying the MVS are the health benefits provided by the system, the reduction of 
monthly costs for heating and/or cooling the dwelling and keeping a constant ambient temperature. An important finding is that the prospects and the buyers of other Lindab products consider the heating/cooling cost reduction as the most important reason for acquiring such a system while Lindab's sales agents and partners believe that the health benefits surpass the financial ones. The most important obstacle in buying the MVS is its cost, the respective value rendering a long return-on-investment time frame. Closely connected with this reality, a payment plan is perceived by the demand side as a solution to mitigate the financial burden. Another important conclusion that can be drawn is that the only group considering the environmental benefits as being important in the buying decision of such a system is the one comprising Lindab's clients, an explanation for this situation being that probably the Romanian construction market is not yet very conscious about the importance of environmental issues.

Based on the findings, Lindab should try to sell its mechanical ventilation system focusing on the financial benefits rendered by the system augmented with the health reasons and constant ambient temperature and stressing the option of the payment plan to reduce the financial strain. Such a marketing approach is reinforced by Lindab's premium brand position on the Romanian market, the brand being often used by prospects and actual buyers as a standard in product comparisons. However, these considerations must be further exploited in qualitative and quantitative studies to comprehend if the uncovered buying motives and their bundling could be used for an enduring market positioning endeavour.

\section{References}

Bernard, H R 2000 Social Research Methods. Thousand Oaks, CA: Sage.

Corbin, J and Strauss, A 2014 Basics of Qualitative Research - Techniques and Procedures for Developing Grounded Theory, 4th ed., Thousand Oaks, CA: Sage.

Coyne, I T 1997 Sampling in qualitative research. Purposeful and theoretical sampling, merging or clear boundaries? Journal of Advanced Nursing, Vol. 26: 623-630.

Creswell, J 1998 Qualitative Inquiry and Research Design. Choosing among Five Traditions. Thousand Oaks, CA: Sage.

Finch, H and Lewis, J 2003 Focus Groups. In Ritchie, J \& Lewis, J (eds.), Qualitative Research Practice - A Guide for Social Science Students and Researchers (pp. 171-198), London: Sage.

Guest, G, Namey, E and McKenna, K 2016 How many focus groups are enough? Building an evidencebase for non-probabilitysamplesizes. Field Methods, published online before print, DOI: http://doi.org/10.1177/1525822X16639015

King, N 2004 Using interviews in qualitative research. In Cassell, C \& Symon, G (eds.), Essential Guide to Qualitative Methods in Organizational Research, London: Sage. 
Kreuger, R A and Casey, M A 2000 Focus Groups: A Practical Guide for Applied Research, 3rd edition. Thousand Oaks, CA: Sage.

Lindab 2016a Interim report January-June 2016. Available at http://www. lindabgroup.com/english/ir/reports/Documents/Interimreport-16-q2.pdf [Last accessed 1 August 2016].

Lindab 2016b About Lindab/ business concept. Available at http://www.lindab. com/global/pro/about-lindab/businessconcept/pages/default.aspx [Last accessed 2 August 2016].

Lindab 2016c About Lindab/ CSR. Available at http://www.lindab.com/global/ pro/about-lindab/csr/pages/default.aspx [Last accessed 2 August 2016].

Lindab 2016d About Lindab/ our products. Available at http://www.lindab. com/global/pro/about-lindab/our-products-solutions/pages/default.aspx [Last accessed 2 August 2016].

Lindab 2016e About Lindab/ Lindab-inside. Available at http://www.lindab. com/global/pro/lindab-inside/Pages/default.aspx [Last accessed 2 August 2016].

Malhotra, K N 2010 Marketing Research, An Applied Orientation, Global Edition, 6th ed., Upper Saddle River, NJ: Prentice Hall.

Marshall, M 1996 Sampling for qualitative research. Family Practice, 13(6): 522-525.

Marshall, B, Cardon, P, Poddar, A and Fontenot, R 2013 Does sample size matter in qualitative research? A review of qualitative interviews in IS research, Journal of Computer Information Systems, 54(1) Fall: 11-22.

Morse, J M 1994 Designing funded qualitative research. In Denzin, N K \& Lincoln, Y S (eds.), Handbook of Qualitative Research (2nd ed.) (pp. 220-235), Thousand Oaks, CA: Sage.

Ritchie, J, Lewis, J and Elam, G 2003 Designing and Selecting Samples. In Ritchie, J \& Lewis, J (eds.), Qualitative Research Practice - A Guide for Social Science Students and Researchers (pp. 77-108), London: Sage.

Sharan, M 2009 Qualitative Research: A Guide to Design and Implementation, San Francisco: Wiley \& Sons. 
